\title{
Acute Inflammatory Dilation of the Cystic Duct Induced by a Stone
}

\author{
Shogo Tanaka Takatsugu Yamamoto Kanji Ishihara Koichi Ono \\ Department of Surgery, Ishikiriseiki Hospital, Higashiosaka, Japan
}

The mean inside diameter of the cystic duct is $3 \mathrm{~mm}$ and the frequency of dilated cystic duct $(>1 \mathrm{~cm})$ induced by a stone is less than $1 \%$. Dilation of $>2 \mathrm{~cm}$ has not been reported. A 55-year-old woman in whom gallstone-induced chronic cholecystitis had been followed for more than 10 years was referred to our hospital. On admission, she had a positive Murphy's sign with low-grade fever. Magnetic resonance cholangiopancreatography demonstrated adenomyomatosis at the neck and fundus of the gallbladder and a stone in the cystic duct (fig. 1). The cystic duct distal to the stone was dilated by $>2 \mathrm{~cm}$ in diameter. Open cholecystectomy with resection of the dilated

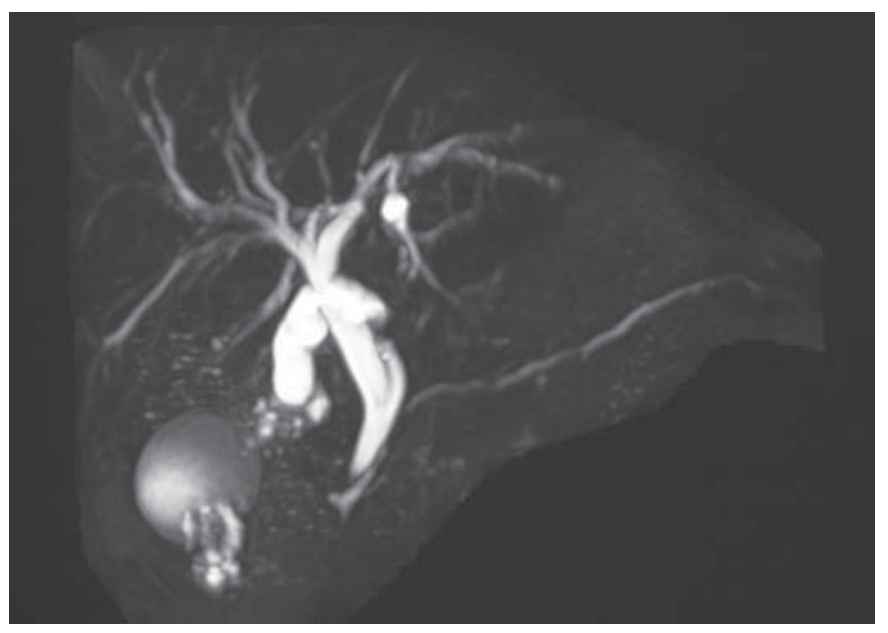

Fig. 1. Magnetic resonance cholangiopancreatography demonstrates adenomyomatosis at the neck and fundus of the gallbladder and a stone obstructs the cystic duct. The cystic duct distal to the stone is dilated by $>2 \mathrm{~cm}$ in diameter.

\section{KARGER}

Fax +41613061234 E-Mail karger@karger.ch www.karger.com
(C) 2008 S. Karger AG, Basel

0253-4886/08/0254-0309\$24.50/0

Accessible online at:

www.karger.com/dsu cystic duct and stone removal were performed under a preoperative diagnosis of chronic cholecystitis (adenomyomatosis) and stone-induced dilated cystic duct. Macroscopically, the gallbladder showed chronic cholecystitis with segmental adenomyomatosis (fig. 2). The cystic duct retained the spiral valve, but was significantly dilated with wall thickening. Histopathologically, chronic cholecystitis with increased Rokitansky-Aschoff sinuses and severe infiltration of neutrophils and macrophages in the cystic duct led to diagnosis of acute inflammatory expansion of the cystic duct. The patient is doing well 6 months postoperatively.

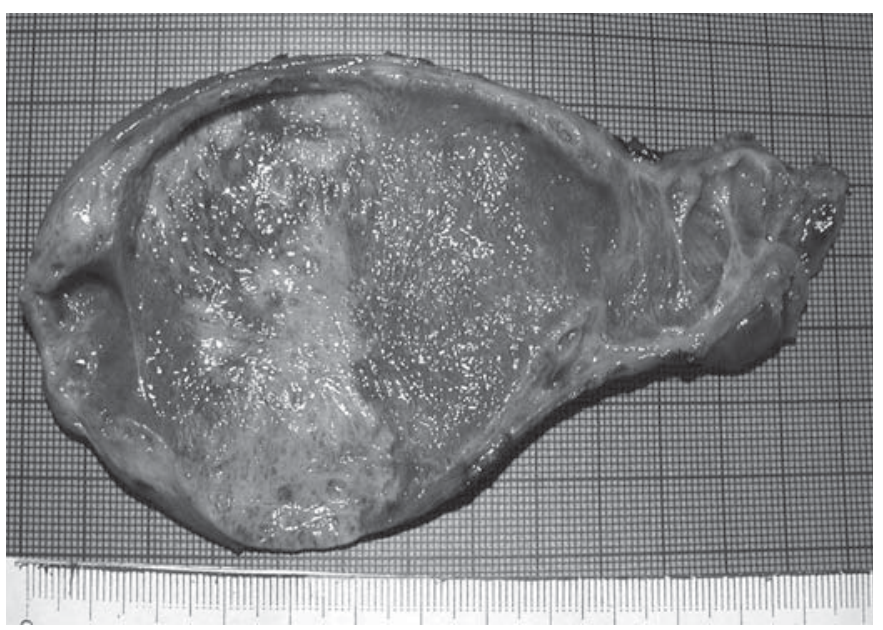

Fig. 2. Macroscopically, the gallbladder shows chronic cholecystitis with segmental adenomyomatosis. The cystic duct retains the spiral valve, but is significantly dilated with wall thickening. 